\title{
Current barriers to treatment for wet age-related macular degeneration (wAMD): findings from the wAMD patient and caregiver survey
}

This article was published in the following Dove Press journal:

Clinical Ophthalmology

I December 2015

Number of times this article has been viewed

\author{
Monica Varano' \\ Nicole Eter ${ }^{2}$ \\ Steve Winyard ${ }^{3}$ \\ Kim U Wittrup-Jensen ${ }^{4}$ \\ Rafael Navarro ${ }^{5}$ \\ Julie Heraghty ${ }^{6}$ \\ On behalf of the wAMD \\ Patient and Caregiver \\ Survey Committee \\ members \\ 'Department of Ophthalmology, \\ Fondazione GB Bietti-IRCCS, Rome, \\ Italy; ${ }^{2}$ Department of Ophthalmology, \\ University of Münster, Münster, \\ Germany; ${ }^{3}$ Department of Policy \\ and Campaigns, Royal National \\ Institute of Blind People, London, UK; \\ ${ }^{4}$ Bayer Pharma AG, Berlin, Germany; \\ ${ }^{5}$ Instituto de Microcirugía Ocular, \\ Barcelona, Spain; ${ }^{6}$ Macular Disease \\ Foundation Australia, Sydney, NSW, \\ Australia
}

Correspondence: Monica Varano

Department of Ophthalmology,

Fondazione GB Bietti-IRCCS, Rome, Italy

$\mathrm{Tel}+39685356727$

Fax +39684242333

Emailm.varano@mclink.it
Purpose: A cross-sectional survey to evaluate the current management of wet age-related macular degeneration (wAMD) and to identify barriers to treatment from a patient and caregiver perspective.

Methods: An ophthalmologist-devised questionnaire was given to a global cohort of patients who were receiving (or had previously received) antivascular endothelial growth factor injections and to caregivers (paid and unpaid) to evaluate the impact of wAMD on their lives.

Results: Responders included 910 patients and 890 caregivers; wAMD was diagnosed in both eyes in $45 \%$ of patients, and $64 \%$ had been receiving injections for $>1$ year. Many caregivers were a child/grandchild ( $47 \%$ ) or partner (23\%) of the patient; only $7 \%$ were professional caregivers. Most (73\%) patients visited a health care professional within 1 month of experiencing vision changes and 54\% began treatment immediately. Most patients and caregivers reported a number of obstacles in managing wAMD, including the treatment itself (35\% and 39\%, respectively). Sixteen percent of patients also missed a clinic visit.

Conclusion: Most patients seek medical assistance promptly for a change in vision; however, about a quarter of them do not. This highlights a lack of awareness surrounding eye health and the impact of a delayed diagnosis. Most patients and caregivers identified a number of obstacles in managing wAMD.

Keywords: antivascular endothelial growth factor agents, patient-reported outcomes, wAMD patient and caregiver survey, wet age-related macular degeneration

\section{Introduction}

The socioeconomic burden associated with wet age-related macular degeneration (wAMD) is predicted to rise as the prevalence increases with aging populations. ${ }^{1-3}$ This will have a major impact on direct and indirect costs, including costs associated with informal care and lost productivity, which are estimated to be in the region of US\$23 billion and $\$ 34$ billion, respectively. ${ }^{4}$

Based on these estimates, it is essential to monitor the effectiveness of long-term management strategies with a view to identifying treatment barriers, particularly from a patient perspective. This is important for newer treatments such as antivascular endothelial growth factor (anti-VEGF) (intravitreal) injections, which have offered remarkable clinical benefits for patients with wAMD. Anti-VEGF agents are known to target a key underlying pathway in the development and progression of wAMD and have been shown to be clinically effective in large-scale studies; ${ }^{5-8}$ however, surveys on long-term treatment patterns indicate that these agents are underutilized in real-life clinical settings. ${ }^{9}$ In addition, few studies have examined the impact of anti-VEGF treatments from a caregiver perspective, with evidence suggesting that the impact may be similar to that 
experienced by caregivers of patients with atrial fibrillation. ${ }^{10}$ Such feedback will be invaluable for identifying any barriers to treatment provision and compliance, which could be addressed by the health provider.

The aim of this noninterventional, cross-sectional survey was to evaluate the impact of wAMD on a global cohort of patients who were currently receiving (or had previously received) anti-VEGF injections. The survey also identified caregivers (both paid and unpaid) and evaluated the effect that caring for someone with wAMD had on them. The survey was conducted via a questionnaire that was devised by ophthalmologists and experts in the field of ophthalmology. This paper reports the findings associated with current approaches to the treatment of wAMD, including diagnosis and follow-up, and obstacles to treatment, from the perspective of both patient and caregiver responders.

\section{Methods}

\section{Study design}

This was a global, noninterventional, cross-sectional survey conducted between June 2012 and September 2012, with data analysis staggered from July 2012 to December 2012. The survey was devised 1) to evaluate the emotional and physical impact of wAMD in patients and caregivers and 2) to identify current approaches to diagnosis and management of wAMD, including barriers to treatment from the perspective of patients and caregivers.

The survey was performed using a questionnaire, which was developed through collaboration between an independent steering committee consisting of ophthalmologists and experts and two research organizations (Blueprint Partnership, Manchester, UK, and Survey Sampling International [SSI], London, UK). The self-administered, 15-minute questionnaire was conducted online via the SSI website. The survey link was soft-launched, allowing a small number of responders to complete the questionnaire so that the data could be checked to ensure accurate capture. For those responders with poor eyesight, face-to-face and telephone collection methods were used, wherein a member of SSI or one of their online partners would read aloud the questions and collect and input the responders' answers. The online, face-to-face, and telephone surveys were translated for each participating country. All responses were anonymous, and all responders provided informed consent. Approval was obtained from the relevant independent ethics committees.

\section{Participants}

The survey was conducted in nine countries (Australia, Brazil, Canada, France, Germany, Italy, Japan, Spain, and the UK). Patients with a wAMD diagnosis who were treated by a health care professional (HCP) and received current or prior anti-VEGF injections to treat their wAMD were included. Caregivers who provided care and support to a patient with wAMD (based on the aforementioned criteria) were also included. Support was defined as assisting with one or more of the following: daily activities (eg, reading, cooking, cleaning, and shopping); driving/traveling with the patient to clinical appointments; being actively involved in clinical appointments; and influencing treatment decisions (eg, advising the patient or helping him or her to understand things and giving an opinion about the treatment he or she will receive). Recruitment of patients and caregivers was conducted using a combination of online recruitment (via the SSI website) and physician referral. Physicians identified suitable patients/caregivers and, with their consent, passed on their details to the research organization.

\section{Questionnaire format}

The questionnaire was divided into patient and caregiver sections (the questions are listed with the tables and figures in the "Results" section). The patient questionnaire comprised two modules. Module A included a number of questions related to initial symptoms, diagnosis (including first $\mathrm{HCP}$ visit), time since diagnosis, and information provided (including source). Module B included a number of questions related to treatment, follow-up, obstacles to managing wAMD, and emotional impact. The caregiver questionnaire was similar, but also included questions on type of support provided. Information on patient-caregiver relationship was also obtained.

\section{Data collection and analysis}

The responders (patients and caregivers) were asked to provide yes/no/not sure answers based on a number of available options or to rate questions using impact scales (positive impact, no impact, negative impact), dependency scales (not dependent, neither dependent nor independent, dependent), or convenience scales (not inconvenient, neither convenient nor inconvenient, inconvenient).

All completed questionnaire data were stored and captured in SPSS format (SPSS Inc., Chicago, IL, USA). Prior to analyses, data checks were undertaken to ensure that all responders met the screening criteria; only eligible responders answered relevant questions, responders who clicked through the survey without giving thoughtful responses were removed, and outliers were removed from relevant questions.

All data were presented as descriptive statistics based on absolute percentages and means. Where possible, data were 
stratified according to whether patients had wAMD in one or two eyes, and these data were compared and analyzed using either a two-sided $t$-test (to compare mean values) or two-tailed $Z$-test (to compare percentages). These analyses were based on the assumption of equal variance with a $5 \%$ significance level $(P<0.05)$. Tests were adjusted using the Bonferroni correction to counteract the problem of multiple and pairwise comparisons. Data analyses were performed in SPSS version 21, and all analyses were documented in syntax files.

\section{Results}

\section{Participants}

A total of 910 patients with wAMD and 890 caregivers completed the questionnaire. The majority of patients $(82.1 \%$; $\mathrm{n}=747 / 910$ ) received support from a caregiver. The caregivers included in the survey were a child or grandchild of the patient (47.3\%; $n=421 / 890)$, partner $(23.3 \%$; $n=207 / 890)$, neighbor/friend/other relatives $(13.7 \% ; n=122 / 890)$, sibling $(6.0 \% ; n=53 / 890)$, or volunteer $(3.3 \% ; n=29 / 890)$. Only $6.5 \%(n=58 / 890)$ were professional (paid) caregivers. The majority of caregivers $(63.0 \% ; n=561 / 890)$ also lived with the patient.

\section{Current approaches to wAMD management \\ Diagnosis}

wAMD was diagnosed in two eyes in $45.1 \%(n=410 / 910)$ of patients and in one eye in $54.9 \%(n=500 / 910)$ of patients. The majority of patients $(74.7 \% ; n=680 / 910)$ had been diagnosed with wAMD for $>1$ year (Table 1$)$. Most patients $(72.9 \%$; $\mathrm{n}=663 / 910$ ) visited an HCP within 1 month of first noticing a change in vision (Table 1). Nearly half of all patients $(41.2 \%$; $n=187 / 454$ ) who delayed visiting an HCP thought that the symptoms would resolve. Significantly more patients with wAMD in one eye delayed visiting an HCP, as they were unaware that their vision had changed $(9.4 \%[n=23 / 245]$ vs $2.4 \%[n=5 / 209]$; $P<0.05$ ) (Table 1). Patients with wAMD in two eyes were more likely to be diagnosed earlier (ie, 1-3 weeks) than the patients with wAMD in one eye (33.9\% [n=139/410] vs $27.2 \%$ [n=136/500], respectively; $P<0.05$ ) (Table 1).

\section{Treatment and follow-up}

The majority of patients $(63.8 \% ; n=581 / 910)$ had been receiving anti-VEGF injections for $>1$ year (Table 2 ). AntiVEGF injections had been started immediately in $54.4 \%$

Table I Diagnosis of wet age-related macular degeneration from a patient perspective

\begin{tabular}{|c|c|c|c|}
\hline Question & $\begin{array}{l}\text { All patients } \\
(\mathrm{N}=9 \mid 0), \mathrm{n}(\%)\end{array}$ & $\begin{array}{l}\text { wAMD (two eyes) } \\
(n=4 I 0), n(\%)\end{array}$ & $\begin{array}{l}\text { wAMD (one eye) } \\
(n=500), n(\%)\end{array}$ \\
\hline \multicolumn{4}{|l|}{ How long have you been diagnosed with wAMD? } \\
\hline$\leq \mathrm{I}$ year & $230(25.3)$ & $85(20.7)$ & $145(29.0)^{*}$ \\
\hline$>1$ to $<3$ years & $420(46.2)$ & $199(48.5)$ & $221(44.2)$ \\
\hline$\geq 3$ to $<6$ years & $203(22.3)$ & $95(23.2)$ & $108(21.6)$ \\
\hline$\geq 6$ years & $57(6.3)$ & $31(7.6)$ & $26(5.2)$ \\
\hline \multicolumn{4}{|c|}{ How long after you first noticed a change in your vision did you first visit an HCP? } \\
\hline$\leq$ I week & $208(22.9)$ & $87(21.2)$ & $|2|(24.2)$ \\
\hline$>$ I week to $\leq \mathrm{I}$ month & $455(50.0)$ & $221(53.9)$ & $234(46.8)$ \\
\hline$>1$ to $\leq 3$ months & $99(10.9)$ & $4 \mathrm{I}(10.0)$ & $58(11.6)$ \\
\hline$>3$ to $\leq 6$ months & $77(8.5)$ & $32(7.8)$ & $45(9.0)$ \\
\hline$>6$ months & $46(5.1)$ & $19(4.6)$ & $27(5.4)$ \\
\hline Do not know & $25(2.7)$ & $10(2.4)$ & $15(3.0)$ \\
\hline \multicolumn{4}{|l|}{ What was the main reason for this delay in visiting an HCP? ${ }^{a}$} \\
\hline Thought symptoms would go away & $\mid 87(4 \mid .2)$ & $101(48.3)^{* *}$ & $86(35.1)$ \\
\hline Not very concerned, assumed it was part of aging process & $90(19.8)$ & $37(17.7)$ & $53(21.6)$ \\
\hline Unable to get earlier appointment & $73(16.1)$ & $32(15.3)$ & $41(16.7)$ \\
\hline Frightened about what it might be & $35(7.7)$ & $23(11.0)^{* *}$ & $12(4.9)$ \\
\hline Unaware vision had changed until it was pointed out to me & $28(6.2)$ & $5(2.4)$ & $23(9.4)^{*}$ \\
\hline Waiting for next scheduled appointment & $21(4.6)$ & $7(3.3)$ & $14(5.7)$ \\
\hline None of the above & $20(4.4)$ & $4(1.9)$ & $16(6.5)^{*}$ \\
\hline \multicolumn{4}{|c|}{ How long was the time between first HCP visit and diagnosis of wAMD? } \\
\hline First visit & $389(42.7)$ & $172(42.0)$ & $217(43.4)$ \\
\hline I-3 weeks & $275(30.2)$ & $139(33.9)^{* *}$ & $136(27.2)$ \\
\hline I-2 months & $185(20.3)$ & $80(19.5)$ & $105(21.0)$ \\
\hline$>2$ months & $47(5.2)$ & $13(3.2)$ & $34(6.8)^{*}$ \\
\hline Not sure & I4 (I.5) & $6(1.5)$ & $8(1.6)$ \\
\hline
\end{tabular}

Notes: alf first visit $\geq 1$ month ( $\mathrm{n}=454$ [all patients], $\mathrm{n}=209$ [two eyes], and $\mathrm{n}=245$ [one eye]). $* \mathrm{p}<0.05$, one eye vs two eyes. $* * \mathrm{p}<0.05$, two eyes vs one eye (two-sided test).

Abbreviations: $\mathrm{HCP}$, health care professional; wAMD, wet age-related macular degeneration. 
Table 2 Treatment and follow-up of wet age-related macular degeneration from a patient perspective

\begin{tabular}{|c|c|c|c|}
\hline Patient questions & $\begin{array}{l}\text { All patients } \\
(\mathrm{N}=9 \mid 0), \mathrm{n}(\%)\end{array}$ & $\begin{array}{l}\text { wAMD (two eyes) } \\
(n=4 \mid 0), n(\%)\end{array}$ & $\begin{array}{l}\text { wAMD (one eye) } \\
(n=500), n(\%)\end{array}$ \\
\hline \multicolumn{4}{|l|}{ How long have you been receiving intravitreal injections? } \\
\hline$\leq \mathrm{I}$ year & $329(36.2)$ & $134(32.7)$ & $195(39.0)^{*}$ \\
\hline$>1$ year to $<3$ years & $391(43.0)$ & $187(45.6)$ & $204(40.8)$ \\
\hline$\geq 3$ years to $<5$ years & $147(16.2)$ & $65(15.9)$ & $82(16.4)$ \\
\hline$\geq 5$ years & $43(4.7)$ & $24(5.9)$ & $19(3.8)$ \\
\hline \multicolumn{4}{|l|}{ Did you receive treatment immediately after being diagnosed? } \\
\hline Yes, $\mathrm{HCP}$ recommended immediate treatment & $495(54.4)$ & $254(62.0)^{* *}$ & $24 I(48.2)$ \\
\hline Yes, HCP scheduled an appointment within I-3 weeks & $332(36.5)$ & $130(31.7)$ & $202(40.4)^{*}$ \\
\hline No, HCP recommended to see how condition progressed & $57(6.3)$ & $20(4.9)$ & $37(7.4)$ \\
\hline No, I was not sure that I wanted treatment and postponed & $15(1.6)$ & $4(1.0)$ & II (2.2) \\
\hline Others & II (I.2) & $2(0.5)$ & $9(1.8)$ \\
\hline \multicolumn{4}{|l|}{ How often do you visit the HCP for eye check-ups? } \\
\hline Every 4-6 weeks & $385(42.3)$ & $185(45.1)$ & $200(40.0)$ \\
\hline Every 2 months & $264(29.0)$ & $137(33.4)^{* *}$ & $127(25.4)$ \\
\hline Every $3-5$ months & $172(18.9)$ & $66(16.1)$ & $106(21.2)$ \\
\hline Every 6-12 months & $72(7.9)$ & $19(4.6)$ & $53(10.6)^{*}$ \\
\hline$<$ I year & $17(1.9)$ & $3(0.7)$ & $14(2.8)^{*}$ \\
\hline \multicolumn{4}{|c|}{ Do you usually have treatment for wAMD every time you go to the hospital/clinic/or your HCP office regarding wAMD? } \\
\hline Yes & $387(42.5)$ & $227(55.4)^{* *}$ & $160(32.0)$ \\
\hline No & $363(39.9)$ & $131(32.0)$ & $232(46.4)^{*}$ \\
\hline No, I usually have a check-up and then a separate appointment & $160(17.6)$ & $52(12.7)$ & $108(21.6)^{*}$ \\
\hline \multicolumn{4}{|l|}{ What effect has your current treatment for wAMD had on your vision? } \\
\hline Return to prediagnosis vision/vision still improving & $203(22.3)$ & $92(22.4)$ & III (22.2) \\
\hline Temporary improvement/stabilization & $470(51.6)$ & $193(47.1)$ & $277(55.4)$ \\
\hline Vision worsened & $214(23.5)$ & $|2|(29.5)$ & $93(18.6)$ \\
\hline Do not know & $23(2.5)$ & $4(1.0)$ & $19(3.8)$ \\
\hline
\end{tabular}

Notes: $* P<0.05$, one eye vs two eyes. $* * P<0.05$, two eyes vs one eye (two-sided test).

Abbreviations: HCP, health care professional; wAMD, wet age-related macular degeneration.

( $\mathrm{n}=495 / 910)$ of patients, and this number was significantly higher in those with wAMD in two eyes compared with one eye $(62.0 \%$ [n=254/410] vs $48.2 \%$ [n=241/500], respectively; $P<0.05)$. Patients usually attended check-ups every 4-6 weeks (42.3\%; $n=385 / 910)$. Patients with wAMD in two eyes were more likely to attend more frequently (every 2 months) compared with patients with wAMD in one eye (33.4\% [n=137/410] vs 25.4\% [n=127/500]; $P<0.05)$. Significantly more patients with wAMD in two eyes compared with one eye had injections at every visit $(55.4 \%$ $[\mathrm{n}=227 / 410]$ vs $32.0 \%[\mathrm{n}=160 / 500] ; P<0.05)$. A temporary improvement or stabilization in vision as a result of current treatment was reported by $51.6 \%$ of patients $(n=470 / 910)$, and $22.3 \%$ of patients $(n=203 / 910)$ reported a return to prediagnosis vision or that their vision was still improving.

Most caregivers always attended appointments (60.1\%; $\mathrm{n}=535 / 890)$ and were involved in discussions about the treatment plan $(83.3 \% ; n=555 / 666$; Table 3$)$. Many caregivers were able to reduce the level of domestic assistance provided after the patient started treatment $(30.2 \%$; $=269 / 890)$, with many also reporting that the patient had a temporary improvement or stabilization in their vision $(53.4 \%$; $n=475 / 890)$. However, a number of caregivers reported that frequent appointments were inconvenient (Figure 1).

\section{Information and support programs}

The level and source of information on wAMD that had been provided is summarized in Table 4 . The main source of information for both patients $(75.6 \% ; n=688 / 910)$ and caregivers $(71.6 \% ; n=637 / 890)$ was the physician, followed by the Internet $(8.6 \%[n=78 / 910]$ and $11.2 \%[n=100 / 890])$. However, only $23.0 \%$ ( $n=209 / 910)$ of patients were enrolled in a patient support program that aimed to provide appointment reminders $(72.2 \%$ [ $\mathrm{n}=151 / 209])$ and emotional support (58.9\% [n=123/209]).

\section{Obstacles to treatment}

Most patients $(65.4 \% ; \mathrm{n}=595 / 910)$ and caregivers $(77.0 \%$; $\mathrm{n}=685 / 890)$ reported a number of obstacles in managing wAMD (Figure 2). For patients, the main barrier was the treatment itself $(34.8 \% ; n=317 / 910)$ (this refers to antiVEGF agents only, and the most common barriers would relate to having injections, frequency of injections, and possible injection-related side effects). Other barriers included treatment costs $(27.8 \% ; \mathrm{n}=253 / 910)$ and finding the right treatment option $(27.4 \%$; $n=249 / 910)$ (this refers to anti-VEGF agents and laser and relates to information on choosing the best option, including whether to have antiVEGF injections [any type], issues relating to frequency of 
Table 3 Treatment and follow-up of wet age-related macular degeneration from a caregiver perspective

\begin{tabular}{|c|c|}
\hline Caregiver questions & $\begin{array}{l}\text { All caregivers } \\
(\mathrm{N}=890), \mathrm{n}(\%)\end{array}$ \\
\hline \multicolumn{2}{|c|}{ How often do you attend appointments for the patient's wAMD? } \\
\hline Always & $535(60.1)$ \\
\hline$\geq 50 \% /$ year & $279(3 \mid .3)$ \\
\hline$<50 \% /$ year & $60(6.7)$ \\
\hline Never & $16(1.8)$ \\
\hline \multicolumn{2}{|c|}{ How often do you have to take the patient to the HCP for their wAMD? } \\
\hline Every 4-6 weeks & $337(37.9)$ \\
\hline Every 2 months & $306(34.4)$ \\
\hline Every $3-5$ months & $165(18.5)$ \\
\hline Every 6-12 months & $65(7.3)$ \\
\hline$<$ I year & $6(0.7)$ \\
\hline Do not know & $\mathrm{II}(\mathrm{I} .2)$ \\
\hline \multicolumn{2}{|c|}{ Did the patient ask your opinion about the best treatment plan for him/her? } \\
\hline Yes & $555(83.3)$ \\
\hline No & III (I6.7) \\
\hline \multicolumn{2}{|c|}{ What impact has the patient's current treatment plan had on his/her vision? } \\
\hline Return to prediagnosis vision/vision still improving & $159(17.9)$ \\
\hline Temporary improvement/stabilization & $475(53.4)$ \\
\hline Vision worsened & $230(25.8)$ \\
\hline Do not know & $26(2.9)$ \\
\hline \multicolumn{2}{|c|}{ Have you been able to reduce the domestic care provided after treatment? } \\
\hline Yes & $269(30.2)$ \\
\hline No, level of care has remained the same & $516(58.0)$ \\
\hline No, level of care has increased & $105(11.8)$ \\
\hline \multicolumn{2}{|c|}{ If vision was worsening, would you encourage patient to speak to the HCP? } \\
\hline Yes & $794(89.2)$ \\
\hline No & $43(4.8)$ \\
\hline Not sure & $53(6.0)$ \\
\hline
\end{tabular}

Note: alf a range of treatments was offered.

Abbreviations: HCP, health care professional; wAMD, wet age-related macular degeneration.

treatments, or if/when to have laser). Several obstacles were reported by a significantly higher proportion of patients with wAMD in two eyes compared with one eye, including the treatment itself $(39.0 \%[\mathrm{n}=160 / 410]$ vs $31.4 \%[\mathrm{n}=157 / 500]$, respectively; $P<0.05)$, and finding the right treatment option (35.1\% [n=144/410] vs 21.0\% [n=105/500]; $P<0.05)$. However, $34.6 \%(n=315 / 910)$ of all patients also reported that they were willing to do whatever it takes to maintain their vision; this was significantly higher for patients with wAMD in one eye than those with wAMD in two eyes $(43.8 \%$ $[\mathrm{n}=219 / 500]$ vs $23.4 \%[\mathrm{n}=96 / 410] ; P<0.05)$. For caregivers, the main barriers were also the patient's treatment itself (38.8\% $[\mathrm{n}=345 / 890])$ and finding the right treatment option for the patient $(31.0 \%[\mathrm{n}=276 / 890])$ (Figure 2$)$.

Despite these obstacles, $84.3 \%(n=767 / 910)$ of patients and $74.2 \%(n=660 / 890)$ of caregivers reported that the patient was compliant with treatment (ie, attended every clinic appointment). For the $15.7 \%(n=143 / 910)$ of patients who missed a clinic appointment, the main obstacles were that the caregiver was unable to take them to the appointment $(25.9 \%$; $n=37 / 143)$, fear about receiving an injection $(21.0 \% ; n=30 / 143)$, and patient illness (reason not stated) $(18.9 \% ; n=27 / 143)$.

Most patients $(56.7 \% ; n=516 / 910)$ were usually taken to the appointment by a caregiver; however, $20.4 \%(n=186 / 910)$ went by public transport, $12.4 \%(n=113 / 910)$ drove themselves, $8.1 \%(n=74 / 910)$ used a taxi, and 2.3\% $(n=21 / 910)$ were taken by an ambulance. Travel time to appointments, however, did not affect the impact that wAMD had on a patient's life (Figure 3).

\section{Discussion}

This global survey provided an overview of the diagnosis and management of wAMD and current barriers to treatment from the perspective of 1,800 patients and caregivers. Responders from nine countries were recruited via physician referral and the Internet, thus representing a broad cross-section of the

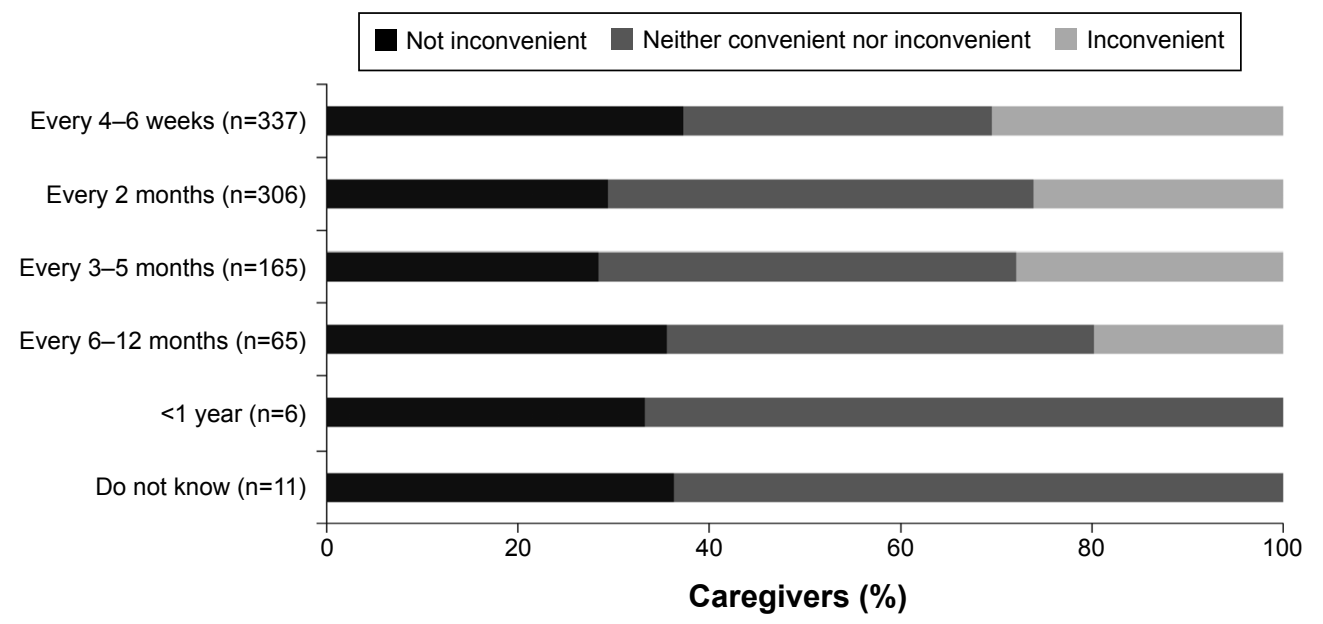

Figure I Association between frequency of health care professional appointments and impact of wet age-related macular degeneration on caregivers ( $\mathrm{N}=890$ ). Note: Questions asked were: do you find the patient's treatment an inconvenience? How often does the patient visit the health care professional for check-ups/about their wAMD?

Abbreviation: WAMD, wet age-related macular degeneration. 
Table 4 Level of information and support provided based on patient and caregiver perspective

\begin{tabular}{|c|c|c|}
\hline & $\begin{array}{l}\text { All patients } \\
(\mathrm{N}=9 \mid 0), \mathrm{n}(\%)\end{array}$ & $\begin{array}{l}\text { All caregivers } \\
(\mathrm{N}=890), \mathrm{n}(\%)\end{array}$ \\
\hline \multicolumn{3}{|c|}{ Were you informed that wAMD is chronic and needs lifelong treatment } \\
\hline Yes & $779(85.6)$ & $778(87.4)$ \\
\hline No & $131(14.4)$ & $112(12.6)$ \\
\hline \multicolumn{3}{|c|}{ Where do you get the majority of your wAMD information from? } \\
\hline Physician & $688(75.6)$ & $637(71.6)$ \\
\hline Nurse & $23(2.5)$ & $21(2.4)$ \\
\hline Brochure/leaflets at HCP clinic & $25(2.7)$ & $36(4.0)$ \\
\hline $\begin{array}{l}\text { Patient association or } \\
\text { advocacy group }\end{array}$ & $35(3.8)$ & $38(4.3)$ \\
\hline Patient support program & $17(1.9)$ & $22(2.5)$ \\
\hline Friends or family & $24(2.6)$ & $16(1.8)$ \\
\hline Internet & $78(8.6)$ & $100(11.2)$ \\
\hline Newspapers/TV/radio & $7(0.8)$ & $6(0.7)$ \\
\hline Others & $5(0.5)$ & $5(0.6)$ \\
\hline Do not seek information & $8(0.9)$ & $9(1.0)$ \\
\hline \multicolumn{3}{|c|}{ Are you enrolled in a patient support program? (patients only) } \\
\hline Yes & $209(23.0)$ & - \\
\hline No & $70 \mathrm{I}(77.0)$ & - \\
\hline \multicolumn{3}{|c|}{ What type of support does the patient support program offer? ${ }^{\text {?a }}$} \\
\hline Appointment reminders & I5I (72.2) & - \\
\hline Monetary support & $77(36.8)$ & - \\
\hline Emotional support & $123(58.9)$ & - \\
\hline Transportation services & $78(37.3)$ & - \\
\hline Visual aides & $69(33.0)$ & - \\
\hline
\end{tabular}

Note: aAll patients $(n=209)$ enrolled in a patient support program.

Abbreviations: HCP, health care professional; wAMD, wet age-related macular degeneration.

WAMD cohort in a general population, and the distribution of patients with AMD in one or two eyes suggests that the sample was not skewed toward most severe patients only. Most patients had also been diagnosed (75\%) and receiving anti-VEGF injections $(64 \%)$ for $>1$ year; they were, therefore, a suitable sample to survey regarding issues related to long-term wAMD treatment. The study found that most patients (73\%) had visited an HCP within 1 month of experiencing vision changes; however, fewer patients were diagnosed (43\%) and treated (54\%) during the first visit. Some patients also delayed visiting an HCP as they thought the symptoms would resolve (41\%) or that it was part of the aging process $(20 \%)$, with $20 \%$ being diagnosed between 1 and 2 months and $8 \%$ receiving delayed treatment.

Other studies have found that delaying diagnosis and subsequent treatment adversely affects the outcomes. ${ }^{11}$ In one study of patients with wAMD (1,149 eyes), those with a shorter waiting time between diagnosis and first injection ( $\leq 10$ days) experienced a smaller loss of visual acuity and greater improvement after first treatment compared with those patients with a longer lag time ( $>10$ days). ${ }^{12}$ Patients with wAMD who were treated early with anti-VEGF injections or usual care also incurred lower total direct costs over a lifetime, including incremental costs per vision-year gained (\$15,279 vs $\$ 57,230$, respectively) and quality-adjusted life years $(\$ 36,282$ vs $\$ 132,281) .{ }^{13}$ Unfortunately, further evaluation of the impact of delayed diagnosis and treatment was beyond the scope of the current survey.

The survey also revealed that $42 \%$ of patients had checkups every 4-6 weeks, and 43\% received treatment at every visit. Overall, $84 \%$ of patients and $74 \%$ of caregivers reported that the patient was compliant with treatment (ie, attended every clinic appointment). Vision had improved as a result of treatment, with $74 \%$ of patients and $71 \%$ of caregivers
A

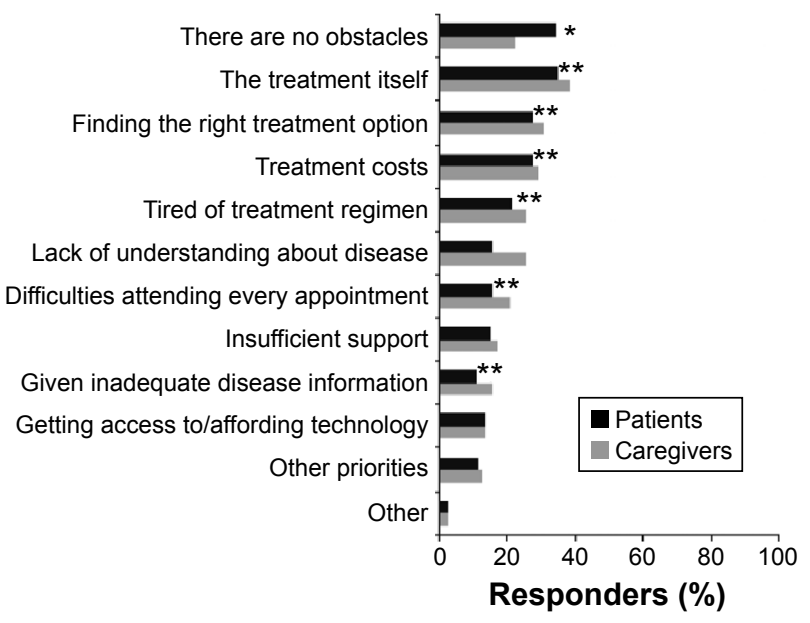

B

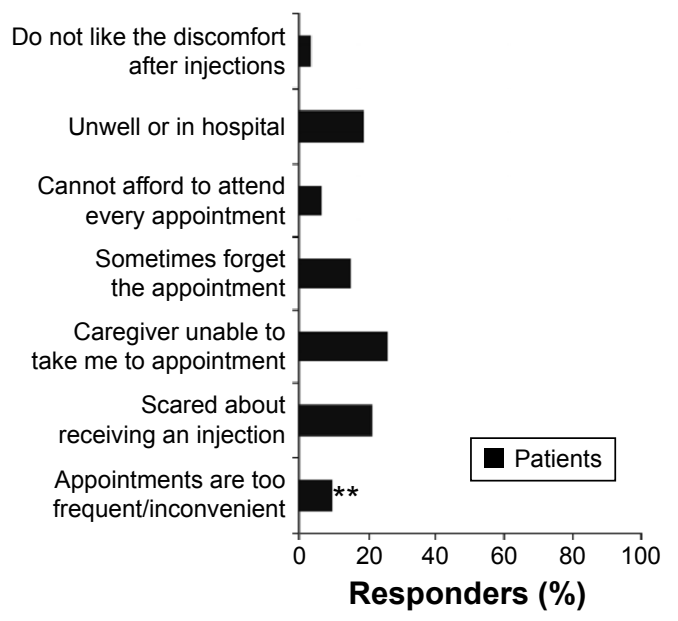

Figure 2 Obstacles to wAMD management and treatment from a patient $(\mathrm{N}=910)$ and caregiver $(\mathrm{N}=890)$ perspective $(\mathbf{A})$, including $(\mathbf{B})$ reasons for difficulty attending every appointment (patients only).

Note: Questions asked were: what do you think are the top three obstacles to coping with/handling your wAMD? (All patients, N=9I0). What do you think are the top three obstacles to managing the patient's wAMD? (All caregivers, $\mathrm{N}=890$ ). ${ }^{*} \mathrm{P}<0.05$ (one vs two eye[s]); ${ }^{* * P}<0.05$ (two vs one eye[s]).

Abbreviations: WAMD, wet age-related macular degeneration. 


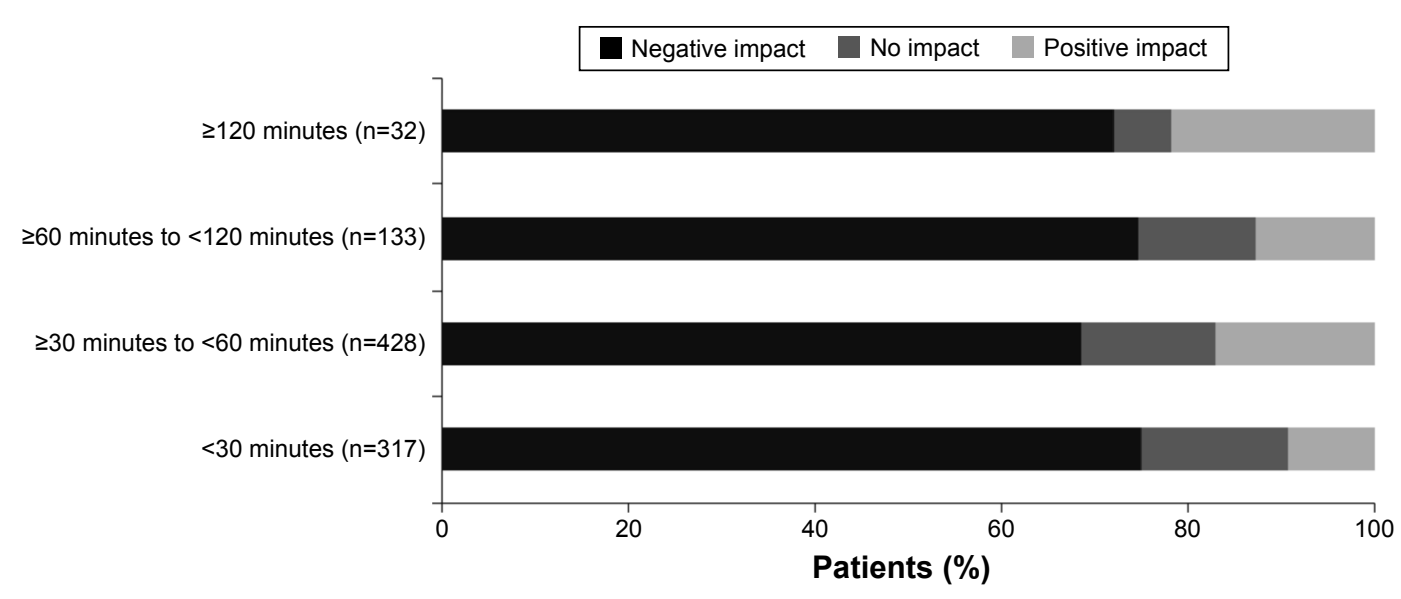

Figure 3 Association between travel time to health care professional appointments and impact of wet age-related macular degeneration on patients ( $\mathrm{N}=9 \mathrm{I0}$ ). Note: Questions asked were: what impact has wAMD had on your life? Approximately how far from the hospital/eye clinic do you live? Abbreviation: wAMD, wet age-related macular degeneration.

reporting a return to prediagnosis vision, vision still improving, temporary improvement, or stabilization. In addition, $30 \%$ of caregivers reduced the level of care provided following patient treatment. Unfortunately, this survey did not monitor the costs associated with patient care and treatment patterns, but a US survey of 803 responders highlighted that the annual costs of caregiving (paid and unpaid) ranged from $\$ 225$ to $\$ 47,086$, depending on visual acuity. ${ }^{14}$

Despite the treatment benefits described here, many patients and caregivers reported a number of obstacles associated with wAMD management that were related to 1) the treatment itself(reasons not stated), 2) finding the right option, and 3) treatment costs. These three obstacles were comparable between patients and caregivers but were significantly higher in patients with wAMD in two eyes compared with one eye. Patients with wAMD in one eye were significantly more likely to do whatever it takes to maintain their vision and to report that there were no obstacles associated with wAMD management. These differences may be linked to the emotional impact of WAMD (particularly the level of depression and disease severity), which is discussed elsewhere. ${ }^{15}$

Current evidence has shown that monthly and as-needed anti-VEGF treatment regimens with ranibizumab are effective, ${ }^{7,8}$ though it might be difficult to replicate monthly clinical regimens in real-life settings. ${ }^{16}$ In the AURA study, which followed 2,227 patients who received one or more ranibizumab injections for up to 2 years, there were fewer injections administered compared with clinical studies (the mean was 5.0 [year 1] and 2.2 [year 2]); the initial improvement observed in visual acuity was not maintained over time, and there was a return to near-baseline values by year $2 .{ }^{17}$ In an attempt to address these issues, two studies focused on quarterly versus monthly dosing with ranibizumab, and though both were effective in ETDRS letters gained, the results with quarterly dosing were less impressive compared with monthly dosing. ${ }^{18,19}$ Unfortunately, the current survey did not explore the effect of different dosing regimens on compliance and treatment barriers, but a different approach (such as treat-and-extend) could address some of the issues raised by the responders.

Not surprisingly, inadequate information on wAMD was also perceived as a barrier by $11 \%$ of patients and $16 \%$ of caregivers, with $16 \%$ of patients and $25 \%$ of caregivers highlighting a lack of understanding about the disease as an issue. Teleconsultation networks have been used successfully in Italian practices, particularly in minimizing the delay between retreatments. ${ }^{20}$ This survey highlights the lack of professional patient support and treatment delays, and both could be further examined in a larger study on the role of telemedicine or with similar initiatives.

Although the survey is valuable in providing an overview of the impact of WAMD on patients and caregivers, it does have a number of limitations inherent with the observational and retrospective design. The questionnaire was devised by experts to cover all aspects of wAMD, but it is not validated and it is still subjective, and some questions may be perceived differently by responders from different countries. The questionnaire did not quantify some of the obstacles associated with wAMD management, and the results may therefore have a number of biases, including selection bias based on the exclusion of nonresponders. It is also not possible to distinguish the severity of the outcomes reported, and it did not include a control. However, the large sample size and use of physician and online referral would capture 
a wide sample, as shown by the distribution of patients with wAMD in one or two eyes.

\section{Conclusion}

In summary, the findings from this survey give a useful overview of the diagnosis, management, and barriers to treatment for wAMD from a patient and caregiver perspective. The results highlight that education in symptom awareness, wider provision of information and support, and tailoring long-term follow-up to adjust for difficulties associated with monthly clinic visits and injections are key areas for improvement.

\section{Acknowledgments}

These data have been presented at the Royal College of Ophthalmologists' Congress (May 20-22, 2014, Birmingham, UK), the German Retina Society Congress (June 13-14, 2014, Düsseldorf, Germany) and the International Society for Pharmacoeconomics and Outcomes Research (November 8-12, 2014, Amsterdam, the Netherlands). The contribution of the IRCCS Fondazione Bietti to this paper was supported by the Italian Ministry of Health and by Fondazione Roma. The survey was sponsored by Bayer HealthCare Pharmaceuticals. Medical writing assistance was provided by PAREXEL and was funded by Bayer HealthCare Pharmaceuticals.

\section{Disclosure}

Monica Varano has served on advisory boards for Bayer, Novartis, and Allergan. Nicole Eter, Steve Winyard, and Rafael Navarro report no conflicts of interest in this study. Kim U Wittrup-Jensen is an employee of Bayer Pharma AG. Julie Heraghty is a CEO of Macular Disease Foundation Australia, which receives funding from Bayer and Novartis.

\section{References}

1. Cardarelli WJ, Smith RA. Managed care implications of age-related ocular conditions. Am J Manag Care. 2013;19(5 suppl):S85-S91.

2. Schmier JK, Jones ML, Halpern MT. The burden of age-related macular degeneration. Pharmacoeconomics. 2006;24(4):319-334.

3. Wong WL, Su X, Li X, Cheung CM, Klein R, Cheng CY, Wong TY. Global prevalence of age-related macular degeneration and disease burden projection for 2020 and 2040: a systematic review and meta-analysis. Lancet Glob Health. 2014;2(2):e106-e116.

Clinical Ophthalmology

\section{Publish your work in this journal}

Clinical Ophthalmology is an international, peer-reviewed journal covering all subspecialties within ophthalmology. Key topics include: Optometry; Visual science; Pharmacology and drug therapy in eye diseases; Basic Sciences; Primary and Secondary eye care; Patient Safety and Quality of Care Improvements. This journal is indexed on Submit your manuscript here: http://www.dovepress.com/clinical-ophthalmology-journal
4. Acess Economics. The Global Economic Cost of Visual Impairment. International Council of Ophthalmology Web site. Available from: http://www.icoph.org/dynamic/attachments/resources/globalcostofvi_ finalreport.pdf. Accessed October 6, 2014.

5. Heier JS, Brown DM, Chong V, et al; VIEW 1 and VIEW 2 Study Groups. Intravitreal aflibercept (VEGF trap-eye) in wet age-related macular degeneration. Ophthalmology. 2012;119(12):2537-2548.

6. Schmidt-Erfurth U, Kaiser PK, Korobelnik JF, et al. Intravitreal aflibercept injection for neovascular age-related macular degeneration: ninety-six-week results of the VIEW studies. Ophthalmology. 2014;121(1):193-201.

7. Brown DM, Kaiser PK, Michels M, et al; ANCHOR Study Group. Ranibizumab versus verteporfin for neovascular age-related macular degeneration. N Engl J Med. 2006;355(14):1432-1444.

8. Rosenfeld PJ, Brown DM, Heier JS, et al; MARINA Study Group. Ranibizumab for neovascular age-related macular degeneration. $N E n g l$ J Med. 2006;355(14):1419-1431.

9. Holekamp NM, Liu Y, Yeh WS, et al. Clinical utilization of anti-VEGF agents and disease monitoring in neovascular age-related macular degeneration. Am J Ophthalmol. 2014;157(4):825-833.

10. Gohil R, Crosby-Nwaobi R, Forbes A, Burton B, Hykin P, Sivaprasad S. Caregiver burden in patients receiving ranibizumab therapy for neovascular age related macular degeneration. PLoS One. 2015;10(6):e0129361.

11. Real JP, Luna JD, Urrets-Zavalia JA, De Santis MO, Palma SD, Granero GE. Accessibility as a conditioning factor in treatment for exudative age-related macular degeneration. Eur J Ophthalmol. 2013;23(6):857-864.

12. Matthe E, Sandner D. Frühzeitige behandlung mit ranibizumab (Lucentis ${ }^{\mathbb{E}}$ ) bei exsudativer AMD. Ophthalmologe. 2011;108(3):237-243.

13. Javitt JC, Zlateva GP, Earnshaw SR, et al. Cost-effectiveness model for neovascular age-related macular degeneration: comparing early and late treatment with pegaptanib sodium based on visual acuity. Value Health. 2008;11(4):563-574.

14. Schmier JK, Halpern MT, Covert D, Delgado J, Sharma S. Impact of visual impairment on use of care giving by individuals with age-related macular degeneration. Retina. 2006;26(9):1056-1062.

15. Gopinath B, Kifley A, Cummins R, Heraghty J, Mitchell P. Predictors of psychological distress in caregivers of older persons with wet age-related macular degeneration. Aging Ment Health. 2015;19(3):239-246.

16. Lad EM, Hammill BG, Qualls LG, Wang F, Cousins SW, Curtis LH. AntiVEGF treatment patterns for neovascular age-related macular degeneration among medicare beneficiaries. Am J Ophthalmol. 2014;158(3):537-543.

17. Holz FG, Tadayoni R, Beatty S, et al. Multi-country real-life experience of anti-vascular endothelial growth factor therapy for wet age-related macular degeneration. Br J Ophthalmol. 2014;99(2):220-226.

18. Regillo CD, Brown DM, Abraham P, et al. Randomized, double-masked, sham-controlled trial of ranibizumab for neovascular age-related macular degeneration: PIER Study year 1. Am J Ophthalmol. 2008;145(2): 239-248.

19. Schmidt-Erfurth U, Eldem B, Guymer R, et al; EXCITE Study Group. Efficacy and safety of monthly versus quarterly ranibizumab treatment in neovascular age-related macular degeneration: the EXCITE study. Ophthalmology. 2011;118(5):831-839.

20. Azzolini C, Torreggiani A, Eandi C, et al. A teleconsultation network improves the efficacy of anti-VEGF therapy in retinal diseases. J Telemed Telecare. 2013;19(8):437-442.

PubMed Central and CAS, and is the official journal of The Society of Clinical Ophthalmology (SCO). The manuscript management system is completely online and includes a very quick and fair peer-review system, which is all easy to use. Visit http://www.dovepress.com/ testimonials.php to read real quotes from published authors. 